\title{
MANYPARTICLE INTERACTIONS AND LOCAL STRUCTURE OF THE METALLIC HYDROGEN AT ZERO PRESSURE
}

\author{
S. D. Kaim ${ }^{\dagger}$, N. P. Kovalenko ${ }^{\dagger \dagger}$, E. V. Vasiliu ${ }^{\dagger}$ \\ ${ }^{\dagger}$ Polytechnic University, 1 Shevchenko Pr., Odesa, UA-270044, Ukraine \\ ${ }^{\dagger \dagger}$ State University, 2 Dvoryans'ka Str., Odesa, UA-270100, Ukraine
}

(Received October 8, 1996)

\begin{abstract}
On the basis of the perturbation expansion for the electron gas energy in the third order to the electron-ion potential the pair and irreducible three-ion interaction potentials in metallic hydrogen are calculated. The irreducible potential of three-ion interaction has attractive nature at short interionic separation and oscillates at large ones. The anisotropic character of the three-ion interaction is shown. The potential relief of the ions pair relative to the third ion is constructed. This relief has some potential wells and valleys which connect them. The important role of the irreducible three-ion interaction in the formation of the local order in three- and four-ion clusters is shown. The potential relief of an equiangular ion triplet relative to the fourth ion is calculated. This relief has a deep potential well for the fourth ion at interionic separation corresponding to the interproton separation in the $\mathrm{H}_{2}$ molecule. The quasiclassical probability of the ion transition into this well is evaluated. The life time of the metallic phase of hydrogen relative to the tunneling nucleation of the $\mathrm{H}_{2}$ molecules is estimated.
\end{abstract}

Key words: metallic hydrogen, three-ion interaction, life time.

PACS number(s): 71.10.+X, 05.30.Fk

\section{INTRODUCTION}

The significance of manyparticle interactions and their role in forming the structure and properties of various condensed systems are not well known yet [1]. For the calculation of manyparticle interaction potentials the knowledge of the linear and nonlinear response functions of the electron gas is necessary. At present the explicit form of a three-pole diagram expression in ring approximation for the homogeneous electron gas is known [2], [3]. It was possible to calculate the equilibrium structures and dynamic properties of simple metal crystals and metallic hydrogen (MH) in the third order to the electron-ion potential (EIP) [3-9] as well as to study three-ion interaction potentials in simple metals $[3,7]$.

The study of the possibility of metastable state of $\mathrm{MH}$ at zero pressure is of special importance [4]. In the case of solid MH calculations have been performed by Brovman and Kagan. They calculated the structure, elastic properties, phonon spectrum of the solid $\mathrm{MH}$ at zero pressure and proved the local stability of the metastable $\mathrm{MH}$ phase in the framework of the manyparticle theory of metals [4]. As it turned out in the third order to the EIP the energy minimum exists for twoparameter hexagonal lattices with a triangular string structure [4]. For all the structures with the energy minimum the elementary cell volume was $\Omega_{0}=20.8 a_{B}^{3}\left(a_{B}\right.$ is the Bohr radius ) and interproton spacing fixed along the $Z$ axis was equal to $d=2.04 a_{B}$. The investigations of the higher order approximations did not change conclusions essentially. It is connected with the fact that eventually a small parameter in the perturbation expansion for the $\mathrm{MH}$ energy at $P=0$ approximately equals $1 / 5[4,6]$. In such a case the sum of all the perturbation expansion terms with the orders $n \geq 5$ gives an error as the dielectric permittivity of the uniform electron gas does [6,9].

The evaluation of the life time of the metastable $\mathrm{MH}$ phase relative to the spontaneous quantum tunneling transition in the insulating phase is among the most important problems. This estimate cannot be made without considering the specific microscopic mechanism of the nucleation of the $\mathrm{H}_{2}$ molecules or the $\mathrm{H}_{2}^{+}$ions in the metallic phase. For the $\mathrm{MH}$ as a system in which the tendency to diatomically ordering exists [8], the calculations of interionic interactions potentials and elucidation of this tendency on the language of groups ion interaction potentials in configurational space are of great interest. In the quantum kinetics of the new phase formation two characteristic times may be distinguished [10]. In the first place the time of transition through a potential barrier (in our case the life time of the metallic phase relative to the nucleation of the $\mathrm{H}_{2}$ molecule). In the second place the total time of the new phase formation. As a consequence of a significant difference between the electron and proton masses during the process of molecular hydrogen phase homogeneous nucleation the characteristic time will be determined by a slow ionic motion in the potential relief created by the nearest neighbouring ions group. Diatomically ordering in $\mathrm{MH}$ corresponds to the possibility of the drawing together the ions to the distance corresponding to the interatomic separation in the $\mathrm{H}_{2}$ molecule. Inasmuch the direct interionic interaction corresponds to the Coulomb repulsion the possibility of drawing ions together may be ensured only by means of indirect ions interaction through the surrounding electron gas.

The purpose of this paper is to consider pair- and three- ion interactions in metastable $\mathrm{MH}$ at $P=0$. The consideration is based on the manyparticle Brovman and Kagan approach [3-6]. The peculiarities of the potential 
relief for the ions group are discovered and interpreted from the point of view of manyparticle tunneling formation of the molecular hydrogen phase.

In sec. 2 expressions for manyparticle potentials are received. In sec. 3 and sec. 4 results of calculations are shown.

\section{MANYBODY INTERACTION IN METALS}

In the framework of manyparticle theory of nontransition metals the energy of electron subsystem in the field of fixed ions in the adiabatic approximation may be written [3]:

$$
\begin{aligned}
E_{e} & =\varphi_{0}+\sum_{n} \varphi_{1}\left(\mathbf{R}_{n}\right)+\frac{1}{2 !} \sum_{m \neq n} \varphi_{2}\left(\mathbf{R}_{n}, \mathbf{R}_{m}\right) \\
& +\frac{1}{3 !} \sum_{m \neq n \neq l} \varphi_{3}\left(\mathbf{R}_{n}, \mathbf{R}_{m}, \mathbf{R}_{l}\right)+\cdots
\end{aligned}
$$

where each term of the (1) series describes the interaction of ion groups through the surrounding electron gas and can be represented as a power series in the EIP [3]. For example

$$
\begin{aligned}
& \varphi_{2}\left(\mathbf{R}_{1}, \mathbf{R}_{2}\right)=\sum_{i=2}^{\infty} \Phi_{2}^{(i)}\left(\mathbf{R}_{1}, \mathbf{R}_{2}\right) \\
& \varphi_{3}\left(\mathbf{R}_{1}, \mathbf{R}_{2}, \mathbf{R}_{3}\right)=\sum_{i=3}^{\infty} \Phi_{3}^{(i)}\left(\mathbf{R}_{1}, \mathbf{R}_{2}, \mathbf{R}_{3}\right)
\end{aligned}
$$

etc. The indirect interaction of two ions in the second order perturbation theory in EIP is well known [11] and equals

$$
\Phi_{2}^{(2)}(R)=\frac{1}{\pi^{2}} \int_{0}^{\infty} d q q^{2} \Gamma^{(2)}(q)|V(q)|^{2} \frac{\sin (q R)}{q R}
$$

where $V(q)=-\frac{4 \pi^{2}}{q^{2}}$ is the form factor of the $\operatorname{EIP} ; \Gamma^{(2)}(q)$ is the sum of two-pole diagrams.

In the third-order perturbation theory in EIP the indirect pair-ion interaction is defined by the expression

$$
\Phi_{2}^{(3)}(R)=\frac{3}{4 \pi^{4}} \int_{0}^{\infty} d q_{1} q_{1}^{2} \int_{0}^{\infty} d q_{2} q_{2}^{2} \int_{-1}^{1} d x V\left(q_{1}\right) V\left(q_{2}\right) V\left(q_{3}\right) \Gamma^{(3)}\left(q_{1}, q_{2}, q_{3}\right) \frac{\sin \left(q_{1} R\right)}{q_{1} R}
$$

where $\Gamma^{(3)}\left(q_{1}, q_{2}, q_{3}\right)$ is the sum of three-pole diagrams; $q_{3}=\left(q_{1}^{2}+q_{2}^{2}+2 q_{1} q_{2} x\right)^{1 / 2}$.

The potential of indirect three-ion interaction after double integration may be written [7]

$$
\begin{aligned}
& \Phi_{3}^{(3)}\left(R_{12}, R_{23}, R_{13}\right)=\frac{3}{2 \pi^{4}} \int_{0}^{\infty} d q_{1} q_{1}^{2} \int_{0}^{\infty} d q_{2} q_{2}^{2} \int_{-1}^{1} d z V\left(q_{1}\right) V\left(q_{2}\right) V\left(q_{3}\right) \Gamma^{(3)}\left(q_{1}, q_{2}, q_{3}\right) \\
& \times \int_{0}^{1} d x \cos \left(x\left(q_{1} R_{12} \frac{R_{12}^{2}+R_{23}^{2}-R_{13}^{2}}{2 R_{12} R_{23}}+q_{2} R_{23} z\right)\right) J_{0}\left(q_{1} R_{12}\left(1-x^{2}\right)^{1 / 2}\left(1-\frac{\left(R_{12}^{2}+R_{23}^{2}-R_{13}^{2}\right)^{2}}{4 R_{12}^{2} R_{23}^{2}}\right)^{1 / 2}\right) \\
& \times J_{0}\left(q_{2} R_{23}\left(1-x^{2}\right)^{1 / 2}\left(1-z^{2}\right)^{1 / 2}\right),
\end{aligned}
$$

where $J_{0}(x)$ is Bessel function of the zeroth order; $z=\cos \left(\mathbf{q}_{1}, \mathbf{q}_{2}\right) ; R_{12}, R_{23}, R_{13}$ are the distances between the vertices of a triangle formed by the protons.

The calculations of potentials were executed at the Wigner-Zeitz radius $r_{S}=1.65$ which corresponds to zero pressure in the zeroth model of a metal [4]. A permittivity function in the Heldart-Vosko form was employed. The collections of potential values were calculated on the set with a step equal to 1 Bohr radius for each dimension. In the drawings of graphs the cubic-splain interpolation was used. 


\section{RESULTS}

Pair interionic potential in the third order has a form

$$
\varphi^{*}(R)=\frac{e^{2}}{R}+\Phi_{2}^{(2)}(R)+\Phi_{2}^{(3)}(R)
$$

where $e$ is the electron charge.

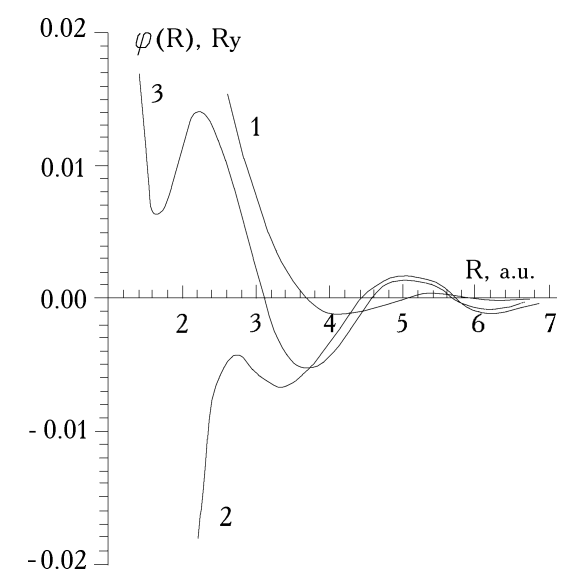

Fig. 1. Potential $\varphi^{*}(R)$ and its components for $r_{S}=1.65$.

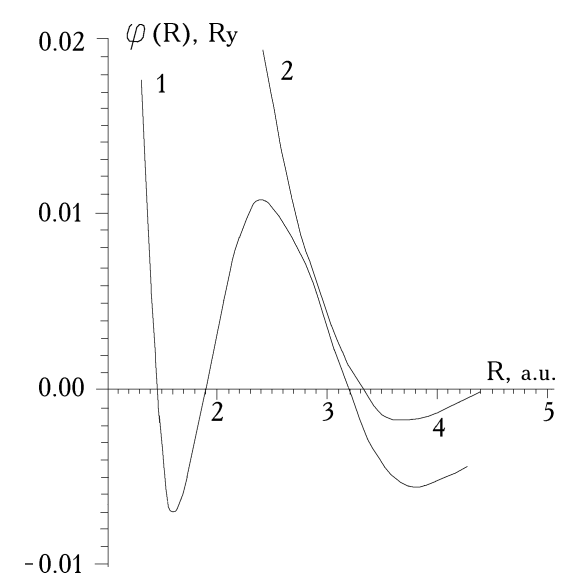

Fig. 2. Potential $\varphi^{*}(R)$ for $r_{S}=1.72$ and $r_{S}=1.55$.

Fig. 1 shows the computed potential $\varphi^{*}(R)$ and its components. Curve 1 corresponds to the contribution $\frac{e^{2}}{R}+\Phi_{2}^{(2)}(R), 2-\Phi_{2}^{(3)}(R), 3-\varphi^{*}(R)$. The pair interionic potential $\frac{e^{2}}{R}+\Phi_{2}^{(2)}(R)$ has no deep potential well. Stevenson and Ashcroft [12] have obtained the pair interproton potential $\frac{e^{2}}{R}+\Phi_{2}^{(2)}$ for $\mathrm{MH}$ at $r_{S}=1.6$ analogous to the one shown in fig. 1 (curve 1 ). The indirect interionic interaction $\Phi_{2}^{(3)}(R)$ has attractive nature and forms a potential well for the nearest neighbouring ion and minimum in the repulsive part of the potential $\varphi^{*}(R)$. The decrease of the density leads to a strong increase of the depth of the minimum in the repulsive part of the potential $\varphi^{*}(R)$. Curve 1 at fig. 2 corresponds to the potential $\varphi^{*}(R)$ at $r_{S}=1.72$. At $r_{S}<1.65$ the minimum in the repulsive part of $\varphi^{*}(R)$ turns shallow and its position shifts towards a smaller $\mathrm{R}$ and at $r_{S}=1.55$ this minimum disappears (curve 2 in fig. 2 ). The position of the minimum in the repulsive part of $\varphi^{*}(R)$ in fig. 1 corresponds to the separation of $R=1.6 a_{B}$. It should be mentioned that the separation between the nuclei in the $\mathrm{H}_{2}$ molecule is equal to $1.4 a_{B}$ and the binding length in the $\mathrm{H}_{2}^{+}$ion is equal to $2 a_{B}$ [13]. The formation of the minimum in the dependence $\varphi^{*}(R)$ at a distance which is smaller than the interproton average distance and a strong dependence of the depth of this minimum on the density of MH may be treated as a tendency to diatomic ordering in the electron-proton plasma.

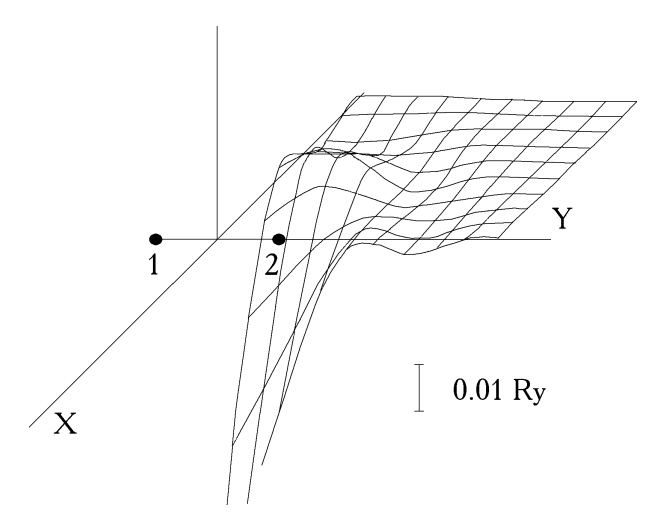

Fig. 3. Irreducible three-ion interaction potential $\Phi_{3}^{(3)}\left(2, R_{13}, R_{23}\right)$.

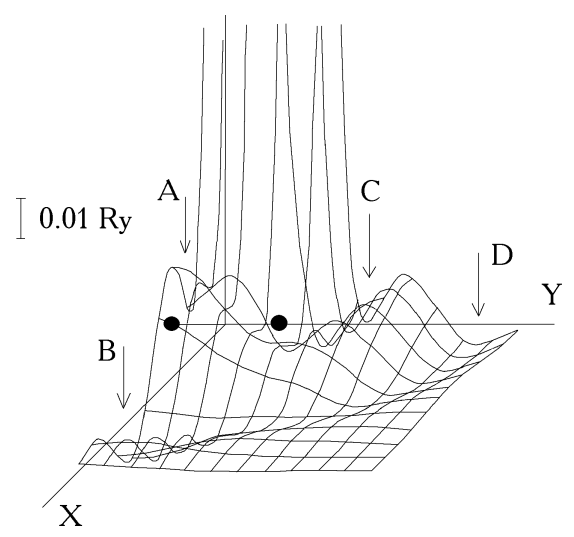

Fig. 4. Potential relief for the 3rd ion in the field of two ions with pair interactions taken into account.

The results of the calculation of the irreducible threeion interaction potential $\Phi_{3}^{(3)}$ for $r_{S}=1.65$ are presented in fig. 3 in the form of the potential relief. The minimal interproton separation in a metallic phase at $P=0$ 
equals to $2.04 a_{B}$ [4]. Two ions are placed in the ordinate axis on a distance $2 a_{B}$ and the third ion is sited in the plane XOY. For small distances the potential $\Phi_{3}^{(3)}\left(2, R_{23}, R_{13}\right)$ has an attractive character. The potential $\Phi_{3}^{(3)}\left(2, R_{23}, R_{13}\right)$ has an anisotropic form and its most rapidly changing takes place in the OX direction. For large distances the potential $\Phi_{3}^{(3)}$ has an oscillatory character. Note that $\Phi_{3}^{(3)}(0,0,0) \simeq-1 R y$.

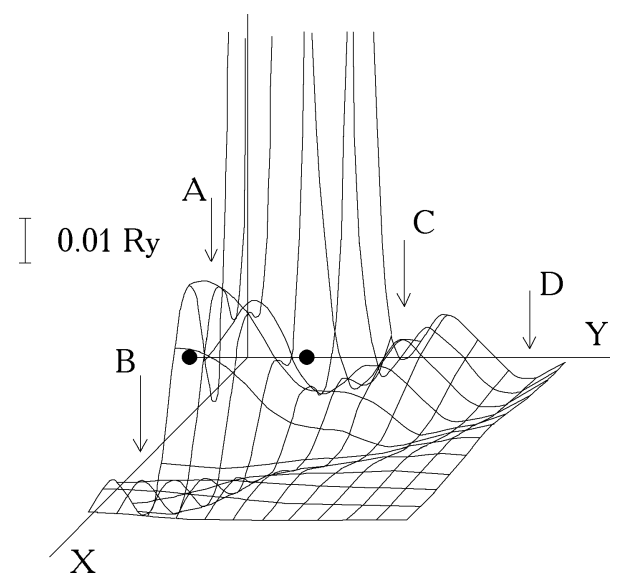

Fig. 5. Potential relief for the 3rd ion in the field of two ions with pair- and three-ion interactions taken into account.

Fig. 4 (geometry coincides with fig. 3) shows potential relief for the $3 \mathrm{rd}$ ion in the fields of two other ions with pair interactions taken into account, that is the potential $\varphi^{*}\left(R_{23}\right)+\varphi^{*}\left(R_{13}\right)$. The minima $\mathrm{B}$ and $\mathrm{D}$ and a valley which connects them correspond to the possible positions of the nearest neighbouring ion in the field of two fixed ions (see fig. 4). It should be noted that ion transition from minimum $\mathrm{B}$ to minimum $\mathrm{D}$ along the valley entails the crossing of the potential barrier with the height of $\sim 1200 \mathrm{~K}$. This situation remains unchanged when irreducible three-proton interaction is taken into account because of the short-acting character of the potential $\Phi_{3}^{(3)}$. The quantum consideration of the ion motion in the field of two fixed ions results in the conclusion about the splitting of the energy level for the ion which is the nearest neighbour for the pair considered. The local minima $\mathrm{A}$ and $\mathrm{C}$ in fig. 4 correspond to the distances to ions 1 and 2 which are less than the interionic average distance.

Fig. 5 shows the potential relief which is created by the ions pair and taking into account pair- and three-ion interactions. It is described by the function $\varphi^{*}\left(R_{23}\right)+\varphi^{*}\left(R_{13}\right)+\Phi_{3}^{(3)}\left(2, R_{23}, R_{13}\right)$. A change of the local minima A, B, C, D positions as compared with fig. 4 is unimportant. As a consequence of a short-range and anisotropic character of the potential $\Phi_{3}^{(3)}$ the depth of the minimum A changes markedly and the depth of the minimum $B$ increases a bit. The ion wave function in potential relief which is shown in fig. 5 has a nonzero value near local minima $\mathrm{A}$ and $\mathrm{C}$. This means that ions have a finite probability draw together with the separation of the order of internuclei distances in $\mathrm{H}_{2}$ or $\mathrm{H}_{2}^{+}$. From comparison of fig. 1 and fig. 5 the conclusion follows that the presence of the the third ion essentially increases this probability.

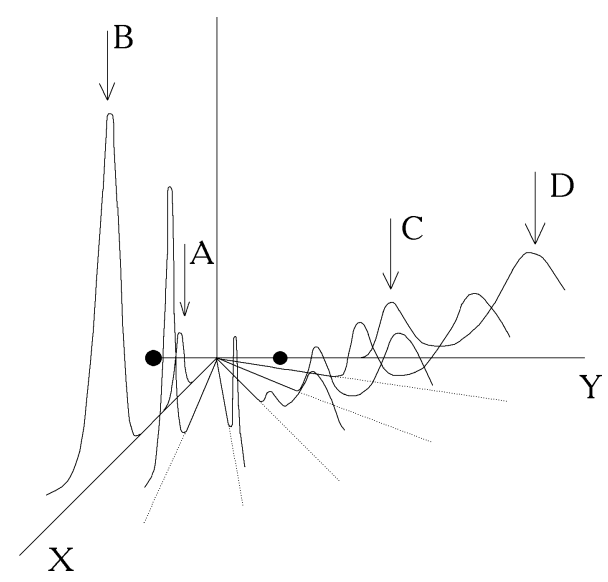

Fig. 6. Distribution of conditional probability density for the ion positions in the ions pair field.

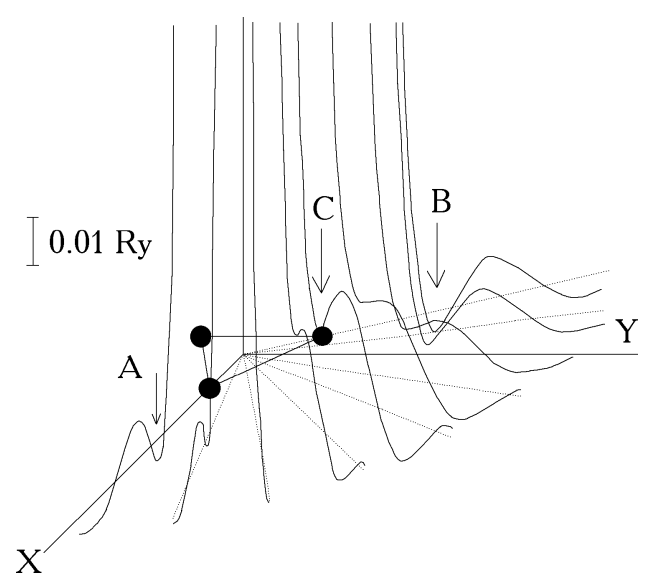

Fig. 7. Potential relief which the three ions create toward the fourth ion (pair interactions taken into account).

Fig. 6 shows computed distribution of conditional probability density for the ion positions in the ions pair field with the pair and three-ion interactions taken into account in Boltzmann approximation at the temperature $T=1000 \mathrm{~K}$. In this approximation the distribution of the conditional probability density may be described in the form of

$$
\begin{aligned}
F_{1}\left(\mathbf{R}_{1} \mid \mathbf{R}_{2}, \mathbf{R}_{3}\right) & \sim \exp \left(-\left(\varphi^{*}\left(R_{12}\right)+\varphi^{*}\left(R_{13}\right)\right.\right. \\
& \left.\left.+\Phi_{3}^{(3)}\left(R_{12}, 2, R_{13}\right)\right) / k T\right)
\end{aligned}
$$

where $k$ is Boltzmann's constant. Local minima of the 
potential relief at fig. 5 correspond to the peaks of the function $F_{1}\left(\mathbf{R}_{1} \mid \mathbf{R}_{2}, \mathbf{R}_{3}\right)$.

It is interesting to consider potential relief which is created by a group of ions. Fig. 7 shows the potential relief which three ions forming equiangular triangle with the side $2 a_{B}$ and placed in the XOY plane create in the same plane towards the fourth ion. In fig. 7 the pair-ion interaction is taken into account and the potential relief is assigned to the function $\varphi^{*}\left(R_{14}\right)+\varphi^{*}\left(R_{24}\right)+\varphi^{*}\left(R_{34}\right)$. It is easy to see the two minima $\mathrm{A}$ and $\mathrm{B}$ and the saddle point $\mathrm{C}$ in the $\mathrm{XOY}$ plane.

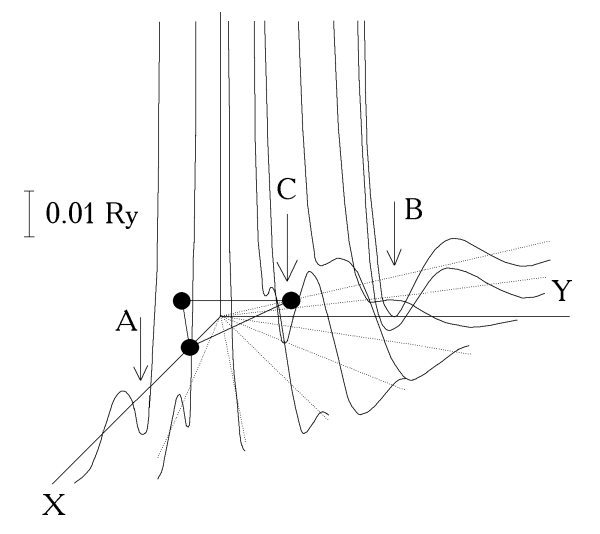

Fig. 8. Potential relief which three ions create toward the fourth ion (pair- and three-ion interactions taken into account).

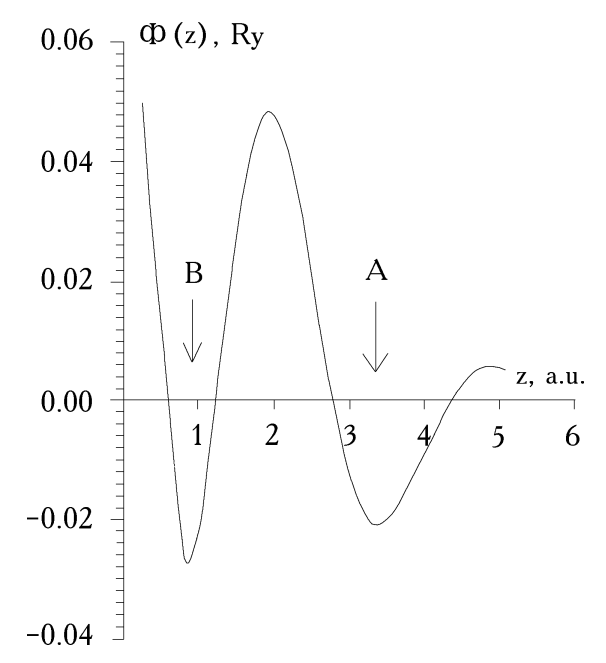

Fig. 9. The dependence of the potential $\Phi(z)$.

The potential relief which is shown in fig. 8 (the geometry is the same as in fig. 7 ) and which is described by the function

$$
\varphi^{*}\left(R_{14}\right)+\varphi^{*}\left(R_{24}\right)+\varphi^{*}\left(R_{34}\right)+\Phi_{3}^{(3)}\left(2, R_{24}, R_{14}\right)
$$

$$
+\Phi_{3}^{(3)}\left(R_{24}, 2, R_{34}\right)+\Phi_{3}^{(3)}\left(R_{14}, R_{34}, 2\right)
$$

takes into account three-ion interactions in the cluster of four ions. Three-ion interactions transform the saddle $\mathrm{C}$ into the local minimum and minima the $\mathrm{A}$ and $\mathrm{B}$ become considerably deeper. This means that an increase of the particles number in the cluster lowers the potential barrier to diatomic ordering.

If three ions are situated in the way shown in fig. 8 and the fourth ion is placed on the $Z$-axis, the dependence of the potential $\Phi(z)$ with pair- and three-ions interactions taken into account is shown in fig. 9. The presence of a deep minimum at $z=a_{B}$ is characteristic peculiarity of this dependence. The second minimum at $z=3.5 a_{B}$ corresponds to the equilibrium position of the fourth ion.

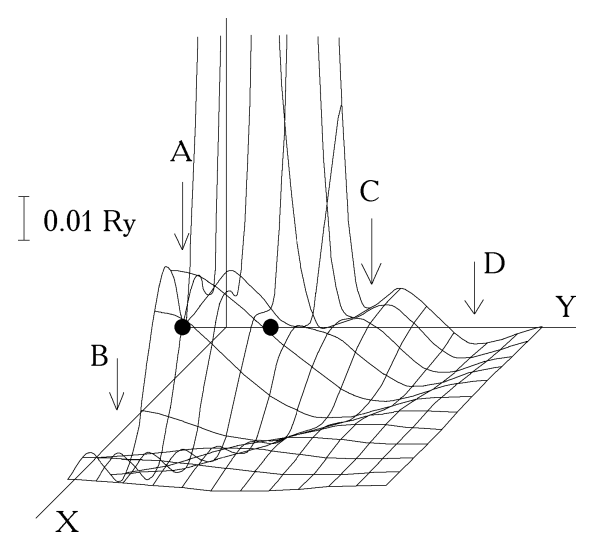

Fig. 10. Potential relief for the 3rd ion in the field of two ions (interionic separation is equal to $1.5 a_{B}$ ) with the pair interactions taken into account.

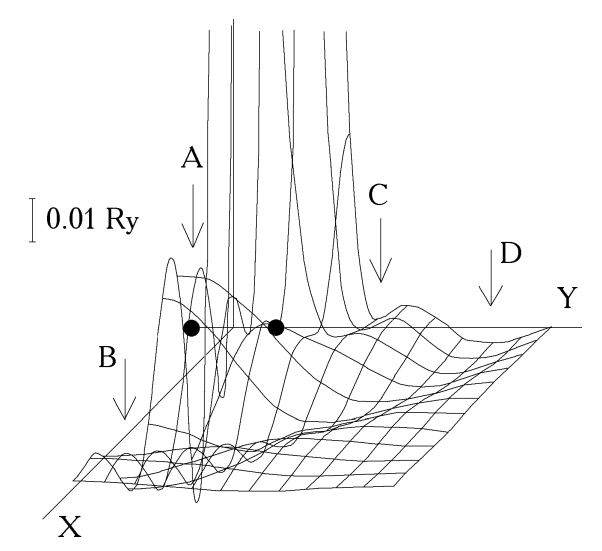

Fig. 11. Potential relief for the 3rd ion in the field of two ions (interionic separation is equal to $1.5 a_{B}$ ) with pair- and three-ion interactions taken into account.

The quantum description of the ion motion in twowell potential of fig. 9 yields the conclusion about a possibility of tunneling transition from the well A to the well B. The probability of ion transition per $1 \mathrm{~s}$ is equal to the product of the ion oscillation frequency in the 
well A and transmission coefficient through the potential barrier. The transmission coefficient can be estimated in quasiclassical approach. The ion frequency of zerooscillation in the well A is equal to $\nu=3.61 \cdot 10^{13} \mathrm{~Hz}$. The transmission coefficient through the potential barrier $D=3.85 \cdot 10^{-12}$. Then the ion's life time $\tau$ in the well A equals $\tau=(D \nu)^{-1}=0.0072 \mathrm{~s}$. If ion transition into the well $\mathrm{B}$ takes place the conditions for the electrons localization on the ion's pairs will be created. Taking into consideration also small characteristic time of an electron subsystem it is possible to consider the obtained time as a characteristic time of the tunneling nucleation of the $\mathrm{H}_{2}$ molecule in $\mathrm{MH}$ at zero pressure. If the identity ions is taken into account it is possible to make a conclusion about a manyionic tunneling mechanism for the metallic hydrogen transition into molecular phase.

The quantum Monte-Carlo simulations of the molecular hydrogen [14] and calculations of the diatomic phase energy as a function of the interproton separation [8] indicate that at a chosen density the molecular unit interproton separation is somewhat less than the neutral molecule separation $1.4 a_{B}$. We calculated the potential relief which is created by the ions pair with the interproton separation $1.5 a_{B}$ (fig. 10, 11). Fig. 10 shows the potential relief for the third ion in the field of two other ions with pair-ion interaction in the third order perturbation theory (analogous to fig. 4). Fig. 11 (geometry coincides with fig. 10) shows the potential relief for the third ion with pair and irreducible threeion interactions taken into account, that is the potential $\varphi^{*}\left(R_{12}\right)+\varphi^{*}\left(R_{23}\right)+\Phi_{3}^{(3)}\left(1.5, R_{13}, R_{23}\right)$. As is easily seen from fig. 10, 11, the irreducible three-ions interaction essentially deepens the potential well A (fig. 11 is analogous to fig. 5). The comparison of fig. 5 and fig. 11 yields the conclusion about a strong dependence on the interproton separation $R_{12}$ of the probability of triplet ions drawing together to the interproton separation as in the $\mathrm{H}_{2}$ molecule. The time of the proton transition from the well B into the well A (fig. 11) cannot be considered as characteristic time of the tunneling nucleation $\mathrm{H}_{2}$ molecule in the metallic phase since interproton separation $R_{12}=1.5 a_{B}$ is less than the minimal interproton separation in the $\mathrm{MH}$ phase at $\mathrm{P}=0$ which equals $2.04 a_{B}$ [4].

\section{DISCUSSION AND CONCLUSIONS}

Our consideration is based on the assumption that the metastable $\mathrm{MH}$ phase exists at $P=0$. The calculations show that irreducible three-ion indirect interactions have a decisive influence on the local structure of the ionic subsystem. The calculations of the possible MH structures at $P=0$ show the tendency for $\mathrm{MH}$ to crystallize in a triangular string with the twodimension periodicity structure [4]. Our calculations of the potential relief which the three ions create towards the fourth ion confirm this conclusion and show that taking into account $\Phi_{3}^{(3)}$ really leads to the formation of the hexagonal struc- ture in the plane of four ions arrangement. Taking into account $\Phi_{3}^{(3)}$ leads to the transformation of the saddle $\mathrm{C}$ (fig. 7) in the local minimum (fig. 8). The minimum $\mathrm{C}$ is formed along the direction which forms the angle of $60^{\circ}$ with the OX axis (the curves on fig. 7, 8 are drawn with a step of $15^{\circ}$ ).

It is possible to observe an interesting peculiarity of the potential relief which a pair of ions creates towards the third ion (fig. 4, 5, 6): the local minima B and D and the valley which connects them and has a saddle point. To make the transition from the minimum $\mathrm{B}$ to that of $\mathrm{D}$ it is necessary to cross over the potential barrier. This means that the energy levels of the third ion in the field of the two fixed ions are split. The quantum effect of the energy levels splitting will be exercised at the temperatures which are less than the potential barrier height. It should be noted here that as a consequence of a shortrange character of the potential $\Phi_{3}^{(3)}$ it has a weak influence on this effect (fig. 4,5 ). It can be supposed that the existence of two-level subsystems in amorphous solids at low temperature is somehow a display of collective quantum oscillatory states of three-particle groups.

In this study the peculiarities of the pair- and threeion interactions are interpreted as the vestiges of the molecular phase in the metastable MH. These peculiarities occur in the metastable metallic phase and are absent at the megabar pressure (fig. 2). This means that an electron-proton system possesses a self-organization effect of "preparing" a transition to the molecular phase. Such an effect increases sharply with the decreasing of the electron gas density.

The probability of the ions' drawing together to the interproton separation as in the $\mathrm{H}_{2}$ molecule depends essentially on the electron gas density. With the density decreasing the probability of the manyionic tunneling nucleation of the molecules $\mathrm{H}_{2}$ sharply increases. Therefore some interest has a study of the life time of metastable MH relative to the homogeneous nucleation of the molecular phase in pressure interval $0<P<P_{t}$ ( $P_{t}$ is the pressure of the molecular hydrogen transition in the metallic phase).

The calculation of the life time of the MH as a macroscopic system calls for the considering both the mechanism of homogeneous nucleation of molecular phase and the kinetics of the formation of the insulating phase droplets in the metastable metal. In this paper we did not consider the kinetic stage. Such a consideration must include a search for the volume and surface free energy minimum of the heterogeneous system consisting of a metastable metal and the insulating droplets. In accordance with the classical and quantum theories of the new phase formation $[10,15,16]$ calculated in this paper the life time of the metallic phase relatively tunneling nucleation of the $\mathrm{H}_{2}$ molecule may differ from the life time of $\mathrm{MH}$ as a macroscopic system by the factor $\sim 3-5$. The new experimental data on the structures and phase diagrams for the molecular hydrogen and deuterium at the megabar pressure $[17,18]$ may be very useful by the consideration of the kinetic stage of the formation and 
growth of the insulating phase droplets in the metastable MH.

\section{ACKNOWLEDGEMENTS}

The authors are grateful to Prof. Yu. P. Krasny, Prof. Z. A. Gurskii and Prof. M. V. Vavrukh for stimulat- ing discussion. This work was supported, in part, by the International Soros Education Program of the International Renaissance Foundation through grants No APU061042 and No SPU062029.
[1] C. A. Croxton, Liquid State Physics. A Statistical Mechanical Introduction (Cambridge University Press, 1974).

[2] P. Lloyd, C. A. Sholl, J. Phys. C 1, 1620 (1968).

[3] E. G. Brovman, Yu. M. Kagan, Usp. Fiz. Nauk 112, 369, (1974) (in Russian).

[4] E. G. Brovman, Yu. M. Kagan, A. Kholas, Zh. Eksp. Teor. Fiz. 61, 2429 (1971) (in Russian).

[5] E. G. Brovman, Yu. M. Kagan, A. Kholas, Zh. Eksp. Teor. Fiz. 62, 1492 (1972) (in Russian).

[6] Yu. Kagan, V. V. Pushkarev, A. Kholas, Zh. Eksp. Teor. Fiz. 73, 967 (1977) (in Russian).

[7] M. Hasegawa, J. Phys. F 6, 649, (1976).

[8] S. Chakravarty, J. H. Rose, D. Wood, N. W. Ashcroft, Phys. Rev. B 24, 1624 (1981).

[9] J. Hammerberg, N. W. Ashcroft, Phys. Rev. B 9, 409 (1974).

[10] I. M. Lifshitz, Yu. Kagan, Zh. Eksp. Teor. Fiz. 62, 385
(1972) (in Russian).

[11] W. A. Harrison, Pseudopotentials in the theory of metals (W. A. Benjamin, Inc., New-York-Amsterdam, 1966).

[12] D. J. Stevenson, N. W. Ashcroft, Phys. Rev. A 9, 782 (1974).

[13] J. N. Murrell, S. F. A. Kettle, J. M. Tedder, Valence theory (J. Wiley and Sons Ltd., London, New-York, Sydney, 1965).

[14] D. M. Ceperley, B. J. Adler. Phys. Rev. B 36, 2092 (1987).

[15] M. Volmer, Kinetics of new phase formation (Moscow, Nauka, 1986) (in Russian).

[16] S. V. Iordansky, A. M. Finkelshtein, Zh. Eksp. Teor. Fiz. 62, 403 (1972) (in Russian).

[17] H. Mao, R. J. Hemley, Rev. Mod. Phys. 66, 671 (1994).

[18] L. Cui, N. H. Chen, S. J. Jeon, I. F. Silvera, Phys. Rev. Lett. 72, 3048 (1994).

\title{
БАГАТОЧАСТИНКОВІ ВЗАЕМОДІЇ ТА ЛОКАЛЬНА СТРУКТУРА МЕТАЛІЧНОГО ВОДНЮ ПРИ НУЛЬОВОМУ ТИСКУ
}

\author{
С. Д. Каім ${ }^{\dagger}$, Н. П. Коваленко ${ }^{\dagger \dagger}$, Е. В. Васіліу ${ }^{\dagger}$ \\ ${ }^{\dagger}$ Політехнічний університет, Украйна, UA-270044, Одеса, пр. Шевченка, 1 \\ ${ }^{\dagger \dagger}$ Державний університет, Україна, UA-270100, Одеса, вул. Дворянсъка, 2
}

На основі теорії збурень для енергії електронного газу в третьому порядку за потенціялом електронйоної взаємодії розраховано потенціяли парної та три-йонної взаємодії в металічному водні. Потенціял нередукованої три-йонної взаємодії має притягувальний характер на малих відстанях між йонами та осцилює на великих відстанях. Показано анізотропний характер три-йонної взаємодії. Побудовано потенціяльний рельєф, створюваний парою йонів відносно третього йона. Цей рельєф має декілька потенціяльних ям та “долину", що іх з'єднуює. Показано важливу роль нередукованої три-йонної взаємодії в формуванні локального порядку в кластерах з трьох та чотирьох йонів. Розраховано потенційний рельєф, створюваний рівностороннім триплетом йонів по відношенню до четвертого йона. Цей рельєф має глибоку потенціяльну яму для четвертого йона на міжпротонних відстанях, що відповідають міжпротонній відстані у молекулі водню. Розраховано квазікласичну ймовірність переходу йона в цю яму. Оцінено час життя металічної фази водню відносно тунельного утворення молекул водню. 